\title{
Predictions on the dynamic behaviour of an aeroelastic model of a television tower in the boundary layer wind tunnel
}

\author{
Elena-Alexandra Chiulan ${ }^{1,}$, , Costin Ioan Coșoiu ${ }^{1}$, Andrei-Mugur Georgescu ${ }^{1}$, Anton Anton ${ }^{1}$, and Mircea Degeratu ${ }^{1}$ \\ ${ }^{1}$ Hydraulic and Environmental Protection Department, Technical University of Civil Engineering Bucharest, Lacul Tei Bvd., no. $122-$ \\ 124, RO 020396, Bucharest, Romania
}

\begin{abstract}
This paper presents the process of making a set of vibration measurements on a model of a television tower in the boundary layer wind tunnel. The main objective of the study is to predict the dynamic behaviour of the full-scale structure under the turbulent wind action, specific for the Bucharest site, in Romania. Wind tunnel tests were performed on a 1:500 scale aeroelastic model, existing at the Aerodynamics and Wind Engineering Laboratory "Constantin Iamandi" from the Technical University of Civil Engineering Bucharest. As a result of the vibration measurements on the tower's model, the dynamic behaviour of the structure on the real scale could be determined by using the conditions and relationships of similitude established between the two, model and prototype (full-scale structure). The experimental analysis made in this study may be very important not only in assessing the dynamic response for a building of such importance, during the preliminary stages, but also can be very helpful for the decision makers involved in the design process to choose which is the best solution for such high and slender structures under the action of turbulent wind.
\end{abstract}

\section{Introduction}

The developments in structural materials, as well as, the advanced technology in civil engineering, have allowed the construction of higher-rise buildings, which are especially prone to dynamic excitations, namely, wind action and earthquakes. With the appearance of manhattanization, the two dynamic excitations are an extremely important issue in the design process of these types of structures. In the case of a very high structure, the action of the wind may have adverse dynamic reactions, that could affect the usefulness of the building, as well as the comfort of its occupants [1-2].

Typically, the dynamic response of buildings is calculated and evaluated based on the numerical codes and mathematical formulas. In general, these standards provide far too little data on high and slender structures. Moreover, special studies are required of all buildings exceeding $200 \mathrm{~m} \mathrm{[1-2].} \mathrm{One} \mathrm{way} \mathrm{to} \mathrm{determine} \mathrm{the}$ dynamic response of a tall structure is to perform experimental tests on a model of the real-scale structure in the boundary layer wind tunnel.

Over time, the problem of wind action on buildings has been carefully analysed. In the last two decades, there have been numerous studies on the behaviour of structures in the boundary layer wind tunnel. [3-16] can be mentioned among the works of great importance in this area.

This paper presents an experimental procedure for observing the dynamic behaviour of a television tower, under the turbulent wind action. The main objective of the sets of vibration measurements made on the model was to obtain the dynamic response of the real-scale structure. For the experimental tests, an already existing 1:500 scale aeroelastic model was used, see Fig. 1 (left and middle side). The model reproduced the $425 \mathrm{~m}$ high reinforced concrete structure of a television tower designed in the early $90 \mathrm{~s}$. The tower was to be located in Bucharest, Romania. The main features of the television tower were: a central tubular core, four vertical latticed elements with decreasing cross-section starting from bottom to top and an axially symmetrical volume between $237 \mathrm{~m}$ and $275 \mathrm{~m}$ for technical facilities [9].
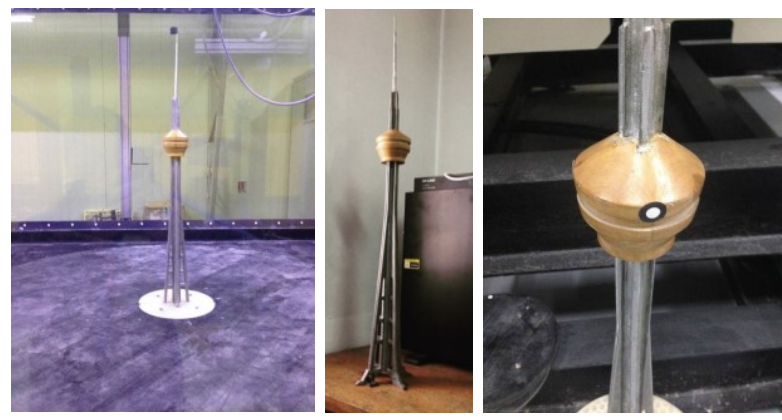

Fig. 1. The aeroelastic model of the television tower, scale 1:500 (left side and middle side) and the Gondola of the television tower (right side) [4-5].

In order to simulate the characteristics of the Bucharest site, we took into account that the reference value of the dynamic pressure that was equal to $0.5 \mathrm{kPa}$, according to Eurocode, so we achieved a reference value

\footnotetext{
* Corresponding author: alexandra.chiulan@hidraulica.utcb.ro
} 
of the wind speed on this site equal $28.28 \mathrm{~m} / \mathrm{s}$. Also, depending on the type's terrain roughness described in Eurocode, Bucharest is placed in the $4^{\text {th }}$ category i.e. an area which at least $15 \%$ of the surface is covered with buildings and their average height exceeds $15 \mathrm{~m}$. In this way, we could get the characteristic curves of this site, in terms of mean wind speed profile and turbulence intensity profile [4-5].

All the experiments were performed at the Aerodynamics and Wind Engineering Laboratory "Constantin Iamandi" from the Technical University of Civil Engineering Bucharest. The area of interest for these experiments was the axially symmetrical volume, named Gondola, see Fig. 1 (right side), at the reference height of $h=425 \mathrm{~mm}$ for the model. We chose the Gondola because it was the most sensitive part of the tower. There were designed to be located the technical emission-reception facilities, water tanks and a rotating restaurant [8].

The similitude conditions are detailed in the first part of the paper. In the second part, the wind tunnel experimental tests which were carried out on the aeroelastic model of the television tower are described. In the third part, the experimental set-up is highlighted. In the final part the results of the vibration measurements and the main discussions and conclusions of this study are presented.

\section{Similitude conditions}

For this study we had to model a physical phenomenon. By using the dimensional analysis, we could determine the similitude conditions between the full-scale structure (prototype) and the model of the television tower. Furthermore, knowing the fact that the wind action on a structure characterized by an elastic behaviour depends on some important parameters, such as: modulus of elasticity of the structure $E_{s}$, air density $\rho_{a}$, wind velocity $u$, characteristic length $l$, dynamic air viscosity $\mu$, gravity $g$, density of the structure $\rho_{s}$ and the logarithmic decrement of damping $\delta_{s}$, the phenomenon could be described by the following physical relation [8], [17]:

$$
f\left(E_{s}, \rho_{a}, u, l, g, \rho_{s}, \delta_{s}\right)=0
$$

By applying the $\pi$ theorem of the dimensional analysis and considering as fundamental parameters $\rho$, $u$ and $l$, so, the following dimensionless groups were established [8], [17]:

$$
\pi_{E_{s}}=E_{s} / \rho u^{2} ; \pi_{g}=g l / \mu^{2}=1 / F r ; \pi_{\rho_{s}}=\rho_{s} / \rho
$$

where: $v$ is the kinematic coefficient of viscosity; $R e$ is the Reynolds number and $\mathrm{Fr}$ is the Froude number.

For the problem at hand: the Froude number can be neglected; the condition $R e=i d e m$ is not important; the condition $\rho_{s} / \rho=i d e m$ can be replaced by the condition $m / \rho l^{2}=i d e m$, where $m$ is the mass per unit length of the structure; the conditions $E_{S} / \rho u^{2}=i d e m$ and $\rho_{s} / \rho=i d e m$ can be replaced by the condition $u / l n=i d e m$, where $n$ is the natural vibration frequency of the structure [8], [17].

Scale relationships considering $\lambda_{l}, \lambda_{l_{s}}$ and $\lambda_{E_{s}}$ as fundamental scales can forward be obtained [8], [17]:

$$
\begin{gathered}
\lambda_{u}=\lambda_{E_{s}} ; \lambda_{f_{s}}=\lambda_{\mu} \lambda_{l_{s}}^{-1} ; \lambda_{A_{s}}=\lambda_{l_{s}} ; \lambda_{a_{s}}=\lambda_{A_{s}} \lambda_{f_{s}}^{2} ; \\
\lambda_{\sigma}=\lambda_{E_{s}} ; \lambda_{\varepsilon}=\lambda_{l_{s}} \lambda_{E_{s}}^{-1} ; \lambda_{\delta_{s}}=1
\end{gathered}
$$

The specification of each of the scales is the following: $\lambda_{l_{s}}$ is the length scale, $\lambda_{u}$ is the velocity scale, $\lambda_{f_{s}}$ is the vibration frequency scale, $\lambda_{A_{s}}$ is the dynamic amplitude scale, $\lambda_{\sigma}$ is the stress scale, $\lambda_{\varepsilon}$ is the unit deformation scale and $\lambda_{\delta_{s}}$ is the logarithmic decrement scale.

Also, the following relationships between the model $(\mathrm{M})$ and the prototype $(\mathrm{P})$ were considered in the process of modelling [8], [17]:

$$
\left(\rho_{s}\right)_{M} \cong\left(\rho_{s}\right)_{P} ;\left(E_{s}\right)_{M} \cong\left(E_{s}\right)_{P} ;\left(\delta_{s}\right)_{M} \leq\left(\delta_{s}\right)_{P}
$$

Table 1. Fundamentals relationships between the scales and the values of the similitude scale for the model $(\mathrm{M})$ and the prototype $(\mathrm{P})$ of the television tower [8], [17].

\begin{tabular}{|c|c|c|c|}
\hline Scale & Relation & $\begin{array}{c}\text { Scale } \\
\text { value }\end{array}$ & $\begin{array}{c}\text { Relationship (P) } \\
\text { and (M) }\end{array}$ \\
\hline Length $\left(\lambda_{l_{s}}\right)$ & - & $1 / 500$ & $\left(l_{s}\right)_{P}=\left(l_{s}\right)_{M} x 500$ \\
\hline $\begin{array}{c}\text { Air density } \\
\left(\lambda_{\rho_{a}}\right)\end{array}$ & - & 1 & $\left(\rho_{a}\right)_{p}=\left(\rho_{a}\right)_{M}$ \\
\hline $\begin{array}{c}\text { Elasticity } \\
\text { modulus } \\
\left(\lambda_{E_{s}}\right)\end{array}$ & - & 1 & $\left(E_{s}\right)_{P}=\left(E_{s}\right)_{M}$ \\
\hline $\begin{array}{c}\text { Decremental } \\
\text { logarithmic } \\
\left(\lambda_{\delta_{s}}\right)\end{array}$ & - & 1 & $\left(\delta_{s}\right)_{P}=\left(\delta_{s}\right)_{u}$ \\
\hline \multicolumn{2}{|c|}{}
\end{tabular}

Table 2. Derivates relationships between the scales and the values of the similitude scale for the model $(\mathrm{M})$ and the prototype $(\mathrm{P})$ of the television tower [8], [17].

\begin{tabular}{|c|c|c|c|}
\hline Scale & Relation & $\begin{array}{c}\text { Scale } \\
\text { value }\end{array}$ & $\begin{array}{c}\text { Relationship (P) and } \\
(\mathrm{M})\end{array}$ \\
\hline $\begin{array}{c}\text { Wind speed } \\
\left(\lambda_{u}\right)\end{array}$ & $\lambda_{U}=\lambda_{E_{s}}$ & 1 & $(u)_{P}=(u)_{M}$ \\
\hline $\begin{array}{c}\text { Structural } \\
\text { density }\left(\lambda_{\rho_{s}}\right)\end{array}$ & $\lambda_{\rho_{s}}=\lambda_{\rho_{a}}$ & 1 & $\left(\rho_{s}\right)_{P}=\left(\rho_{s}\right)_{M}$ \\
\hline $\begin{array}{c}\text { Oscillations of } \\
\text { structure }\left(\lambda_{f_{s}}\right)\end{array}$ & $\lambda_{f_{s}}=\lambda_{u} \lambda_{l_{s}}^{-1}$ & 1 & $\left(f_{s}\right)_{P}=\left(f_{s}\right)_{M} / 500$ \\
\hline
\end{tabular}




\begin{tabular}{|c|c|c|c|}
\hline $\begin{array}{c}\text { Oscillation } \\
\text { periods }\left(\lambda_{T_{s}}\right)\end{array}$ & $\lambda_{T_{s}}=\lambda_{f_{s}}{ }^{-1}$ & 500 & $\left(T_{s}\right)_{P}=\left(T_{s}\right)_{M} \times 500$ \\
\hline $\begin{array}{c}\text { Dynamic } \\
\text { amplitudes of } \\
\text { structure }\left(\lambda_{A_{s}}\right)\end{array}$ & $\lambda_{A_{s}}=\lambda_{l_{s}}$ & $1 / 500$ & $\left(A_{s}\right)_{P}=\left(A_{s}\right)_{M} \times 500$ \\
\hline $\begin{array}{c}\text { Acceleration of } \\
\text { the structure } \\
\text { oscillation } \\
\left(\lambda_{a_{s}}\right)\end{array}$ & $\lambda_{a_{s}}=\lambda_{A_{s}} \lambda_{l_{s}}{ }^{2}$ & $1 / 500$ & $\left(a_{s}\right)_{P}=\left(a_{s}\right)_{M} / 500$ \\
\hline
\end{tabular}

Taking into account all the above relationships, Table 1 and Table 2 accurately details the relationships and values of the scales for the model and the prototype [17]. After performing the experiments on the tower's model, the same relationships are used to transpose the results for the prototype.

\section{Wind tunnel tests}

Wind tunnel tests were conducted in the new refurbished boundary layer wind tunnel TASL1-M at the Aerodynamics and Wind Engineering Laboratory "Constantin Iamandi", from the Technical University of Civil Engineering Bucharest. The wind tunnel active section is $20.40 \mathrm{~m}$ long, with a cross-section of $1.75 \mathrm{~m}$ by $1.75 \mathrm{~m}$. For this study we used a geometrical scale $\lambda_{l_{s}}=1 / 500$ [8], [17]. This way, the blockage effects in the limited flow cross-section were avoided.

The model was constructed as an aeroelastic model, which respected the geometry of the full-structure, for both aerodynamics surfaces and details. The materials used for correct distribution of the model mass were an aluminium alloy ATS12 and wood. Thus, the similitude conditions between the model and the prototype were met [8], [17].

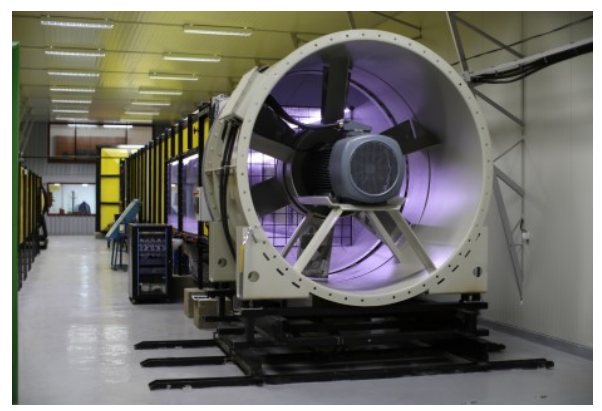

Fig. 2. The new refurbished boundary layer wind tunnel TASL1-M [4-5].

The boundary layer wind tunnel TASL1-M, see Fig. 2 , has the main quality of being equipped with a variable roughness system that can correctly model the atmospheric boundary layer according to Eurocode (in terms of mean wind speed profile and turbulence intensity profile), for different locations [1-2]. TASL1-M is also equipped with an axial fan of $200 \mathrm{~kW}$.

All the experimental tests made for this analysis were carried out in a turbulent flow. We used only the variable roughness system to simulate the characteristics for the Bucharest site. Moreover, during the calibration process the property of internal similitude in the wind tunnel was observed. This means that for a certain height of the variable roughness, the non-dimensional mean wind speed profile and the turbulence intensity profile are the almost same (except for a small area near the ground), with respect to the frequency shift of the axial fan [4-5]. This property is obvious from Fig. 3.

The general logarithmic law used for the mean wind speed profile is defined by the expression [1-2]:

$$
v_{m}(z)=\frac{v_{*}}{k} \cdot\left(\ln \frac{z}{z_{0}}\right)
$$

where: $v_{m}$ is the mean wind speed; $k$ is the von Kármán constant, $k=0.4[1-2] ; \quad v_{*}$ is the shear velocity; $z_{0}$ is the roughness height, $z_{0}=1.0[1-2]$.

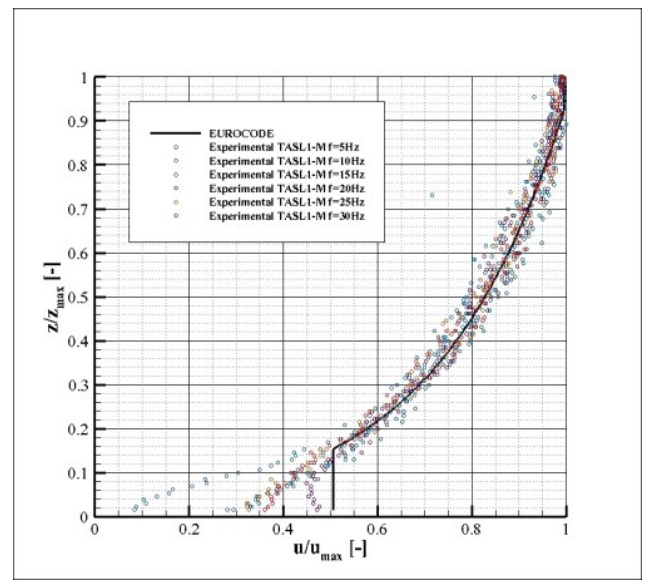

Fig. 3. Mean wind speed profile for Bucharest site (Eurocode and experimental tests in TASL1-M) [4-5].

The turbulence intensity profile was defined by the following mathematical equation [1-2]:

$$
I_{v}(z)=\frac{\sigma_{v}}{v_{m}(z)}=\frac{\sqrt{\beta}}{2.5 \ln \left(\frac{z}{z_{0}}\right)}
$$

where: $I_{v}$ is the turbulence intensity of wind; $\sqrt{\beta}$ is the proportionality factor that varies depending on the roughness of the terrain $\left(z_{0}=1.0[1-2]\right)$.

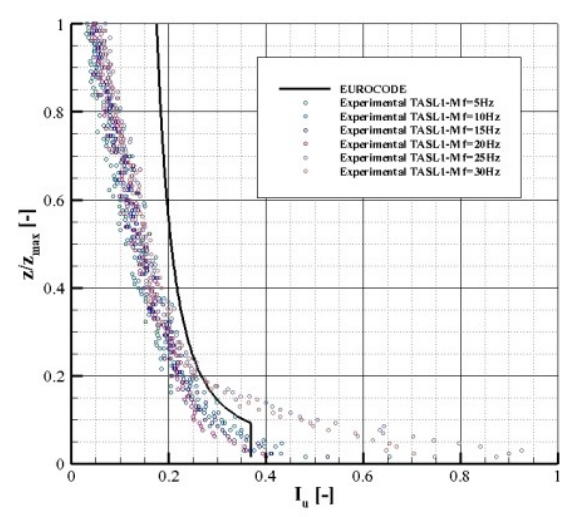

Fig. 4. Turbulence intensity profile for Bucharest site (Eurocode and experimental tests in TASL1-M) [4-5]. 
For the power spectrum of the longitudinal wind speed at the reference height of the Gondola, $h=495 \mathrm{~mm}$, the next mathematical formula was used [1-2]:

$$
S_{L}(z, n)=\frac{6.8 f_{L}(z, n)}{\left(1+10.2 f_{L}(z, n)\right)^{5 / 3}}
$$

where: $S_{L}(z, n)$ is the power spectral density; $f_{L}(z, n)$ is the non-dimensional frequency.

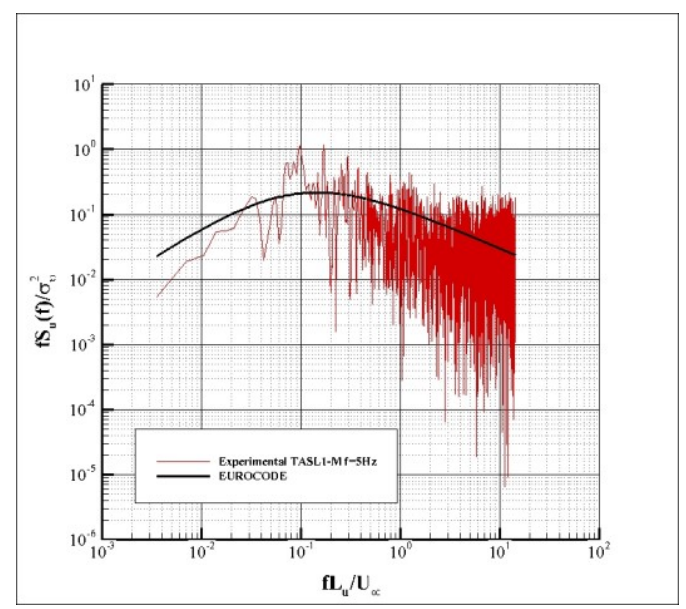

Fig. 5. Power spectrum of the longitudinal wind speed at the reference height $h=425 \mathrm{~mm}$ in the experimental vein of TASL1-M for $u_{\infty}=3 \mathrm{~m} / \mathrm{s}$ [4-5].

In order to calibrate the wind tunnel three different roughness heights were considered, namely $0 \mathrm{~mm}, 50$ $\mathrm{mm}$ and $100 \mathrm{~mm}$. Superposing experimental measured values [4-5] over the above-mentioned Eurocode curves the best match was found for the roughness height of $100 \mathrm{~mm}$. The profiles for the mean wind speed and turbulence intensity are plotted in Fig. 3 and Fig. 4.

Furthermore, the power spectrum of the longitudinal wind speed for an axial fan frequency equal to $5 \mathrm{~Hz}$ corresponding to a wind speed $u_{\infty}=3 \mathrm{~m} / \mathrm{s}$ in the free stream, at the reference height of the Gondola, $h=425$ $m m$, is shown in Fig. 5.

For the vibration measurements on the aeroelastic model of the television tower in the boundary layer wind tunnel, the only orientation was the one presented in Fig. $3[4-5]$.

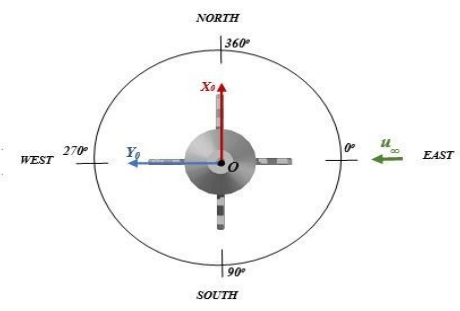

Fig. 6. The tower's orientation in the boundary layer wind tunnel TASL1-M with respect to the wind direction [4-5].

\section{Experimental set-ups}

The main purpose of the experimental tests was to predict the dynamic response of the full-scale structure of the television tower by making vibration measurements on the aeroelastic model in the boundary layer wind tunnel. Thus, for vibration measurements a Laser Doppler vibrometer, type OMS Laser Point LP01 was used. Because both laser heads of the vibrometer could not be fixed on the transverse system from the experimental vein of the wind tunnel, vibration measurements had to be performed on one direction at a time, positioning only one laser head on the traverse system of the wind tunnel. The position of the model in the boundary layer wind tunnel can be seen in Fig. 6 .

To comply with the previously established conditions (related to the mean wind speed profile and the turbulence intensity profile), the variable roughness was raised to $100 \mathrm{~mm}$, see Fig.7. Moreover, to achieve experimental data with high accuracy at the reference height $h=425 \mathrm{~mm}$, a marker was applied at the Gondola's level. Finally, 12 sets of vibration data, 6 for each considered direction were measured.
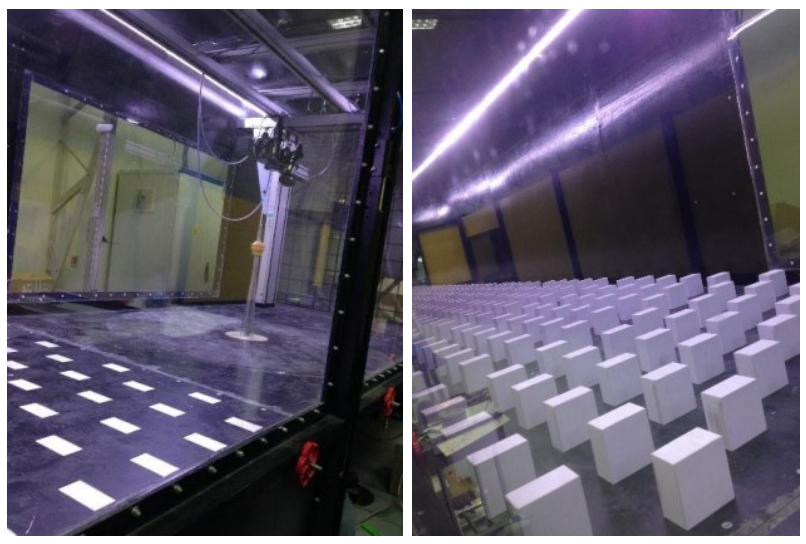

Fig. 7. The television tower model orientation in the boundary layer wind tunnel TASL1-M with respect to the wind direction (left side) and the variable roughness raised up at $100 \mathrm{~mm}$ (right side) [4-5]

The parameters achieved for each vibration measurement were time, voltage, frequency and an FFT. Based on the four parameters and using the below mathematical formulas, we could determine the determine the displacements, velocities and dynamic accelerations for the model of the television tower under the simulated wind action:

$$
\begin{aligned}
& v[\mathrm{~mm} / \mathrm{s}]=\text { Voltage } \cdot 5.093 \\
& d[\mathrm{~mm}]=\left(v_{1}-v_{0}\right) \cdot\left(t_{1}-t_{0}\right) \cdot d_{0} \\
& a\left[\mathrm{~mm} / \mathrm{s}^{2}\right]=\left(v_{1}-v_{0}\right) /\left(t_{1}-t_{0}\right)
\end{aligned}
$$

where: $d$ is the displacement; $\quad v$ is the velocity; $a$ is the acceleration; 5.093 is the calibration constant of the laser according to the speed domain chosen for the vibration measurements.

For each of the 12 vibration measurements were achieved time-dependent signals like those plotted in Fig. 8, Fig. 9 and Fig. 10. 


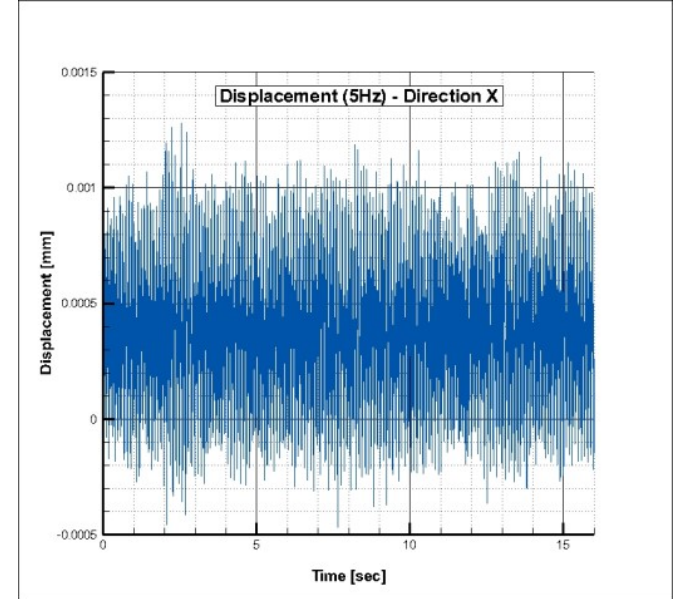

Fig. 8. Time-dependent signals achieved from the vibration measurements for displacement.

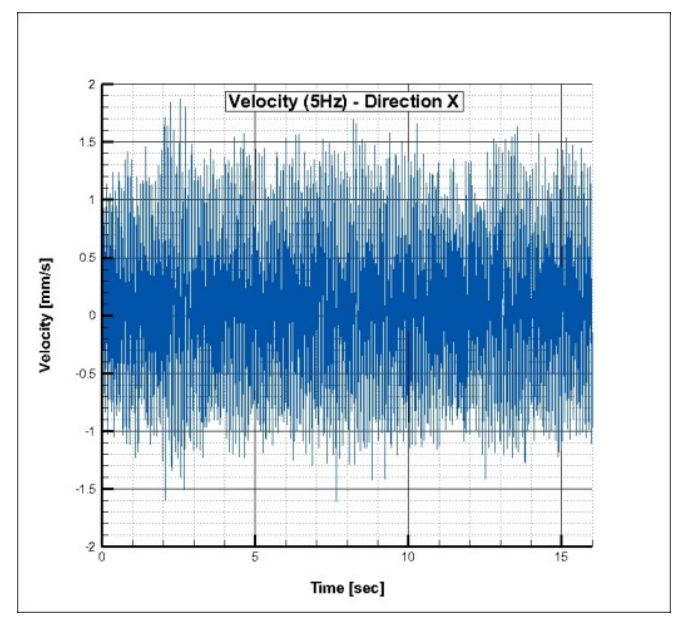

Fig. 9. Time-dependent signals achieved from the vibration measurements for velocity.

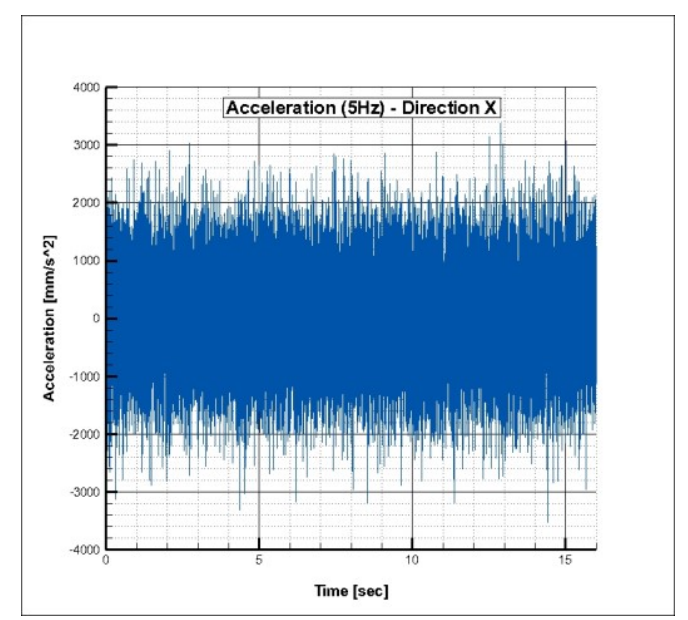

Fig. 10. Time-dependent signals achieved from the vibration measurements for accelaration.

\section{Results and discussions}

\subsection{Results}

For each individual time-dependent signal the maximum, minimum, average, root-mean-square, positive mean and negative mean values were calculated. Each resulting value was then transposed to prototype scale according to the similitude criteria presented in section 4 .

For the graphical representation of the abovementioned results, we considered that the $X$ axis is represented by the mean velocity in the boundary layer wind tunnel TASL-1M and the $\mathrm{Y}$ axis is represented by the specific values of displacement or dynamic acceleration [4-5].

\subsection{Discussions}

The most relevant results of this study are presented in Fig. 11, Fig. 12 and Fig. 13.

These results were obtained for the corresponding prototype, wind speed equal to $16.78 \mathrm{~m} / \mathrm{s}$.

Furthermore, by analysing the results, we could say that of special interest for these experimental tests were the displacements and the dynamic accelerations of the tower. Of great importance are the displacements values, only if these values are compared with the static displacements values corresponding to the same speed of the undisturbed current upstream of the structure.

Analysing the graphical representations, we could note that the values of displacements and dynamic accelerations increase when the wind speed increases.

In terms of dynamic accelerations of the full-scale structure, these values reach a maximum of 0.1156147 $\mathrm{m} / \mathrm{s}^{2}$ for the $X$ direction and $0.0734909 \mathrm{~m} / \mathrm{s}^{2}$ for the $Y$ direction for the wind speed equal to $16,78 \mathrm{~m} / \mathrm{s}$, see Fig. 9.

Regarding the dynamic displacements if we compute these values with respect to the values of the static displacements of the real-scale television tower, a value of maximum $0.015806132 \mathrm{~m}$ on the $\mathrm{X}$ direction and $0.006767055 \mathrm{~m}$ for the $\mathrm{Y}$ direction is achieved for 16,78 $\mathrm{m} / \mathrm{s}$ wind speed.

If dynamic displacements are computed with respect to the undisturbed position of the prototype, the values are equal to $0.015806132 \mathrm{~m}$ for the $\mathrm{X}$ direction and $0.002408609 \mathrm{~m}$ for the $\mathrm{Y}$ direction for the $16,98 \mathrm{~m} / \mathrm{s}$ wind speed.

The experimental tests also revealed low values of the static and dynamic displacements and low values of the accelerations for the full-scale structure of the television tower. These low values of the displacements and accelerations are somehow justified because the experimental tests had been carried out in an experimental vein, without spires (turbulence generators). The blocks of variable roughness were the only device used to simulate the atmospheric boundary layer for the Bucharest site. This way, the flow was characterized by a low level of turbulence, but these were the initial conditions imposed. So, under these conditions, the tower could not reach the inertial subdomain (characterized by higher values of Reynolds number), which would lead to higher values of the experimentally determined results.

In addition, due to the specific conditions for the Bucharest site vibration measurements could not be performed at a Reynolds number corresponding to the 
separation of alternating vortices with separation frequency equal to the natural frequency of the tower. This fact could lead to important oscillations of the structure. For all the results the conditions of human comfort are entirely satisfied for the selected location of the prototype, for the maximum wind speed of 16,98 $\mathrm{m} / \mathrm{s}$.

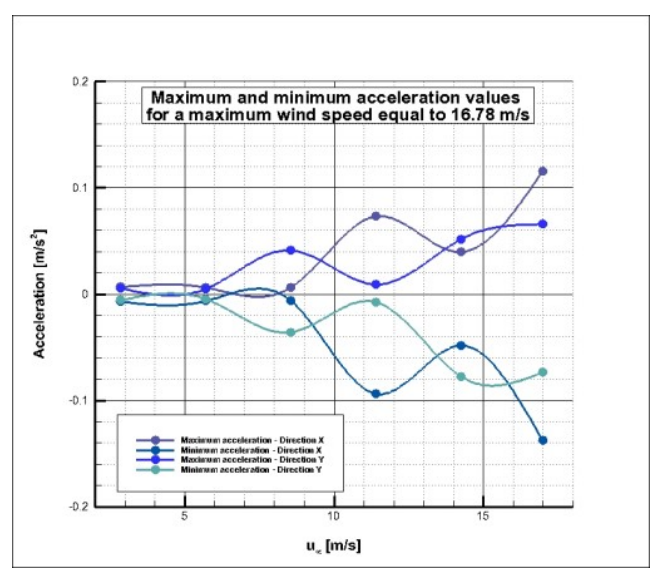

Fig. 11. Maximum and minimum acceleration values for the prototype for both considered directions.

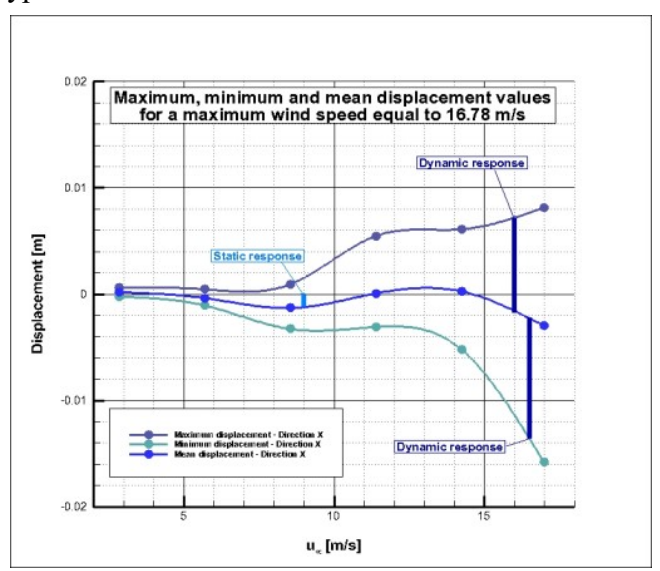

Fig. 12. Maximum, minimum and mean displacement values for the prototype for the $\mathrm{X}$ direction.

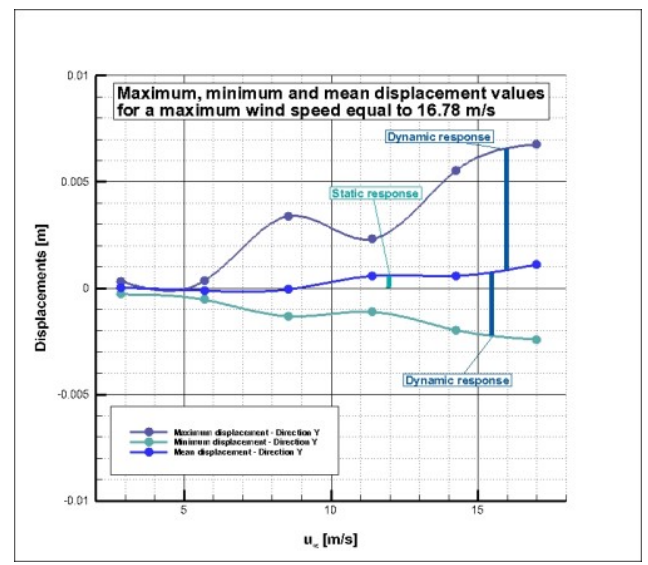

Fig. 13. Maximum, minimum and mean displacement values for the prototype for the $\mathrm{Y}$ direction.

\section{Conclusions}

This paper presents the results of a set of vibration measurements made on an aeroelastic model of a television tower under the turbulent wind action to predict the behaviour of the full-scale structure.

In order to see exactly the behaviour of the full-scale structure we determined the similitude conditions between the aeroelastic model and the prototype. All the results of the vibration measurements we transposed to the prototype scale.

For this study, a comparison was performed between the wind tunnel data and the data calculated according to Eurocode (for the specific location of the tower) for the mean wind speed profiles and the turbulence intensity profiles. The best match between the two different sets of data was obtained for a height of the variable roughness equal to $100 \mathrm{~mm}$.

A Laser Doppler vibrometer type OMS LaserPoint LP01 was used to perform the vibration measurements in the wind tunnel. All the equipment used for these experimental tests was available in the Aerodynamics and Wind Engineering Laboratory "Constantin Iamandi" of the Technical University of Civil Engineering Bucharest.

Furthermore, to predict the behaviour of the prototype under turbulent flow, the experimental data acquired during the vibration measurement were processed by determining the maximum, minimum, average, root-mean-square, positive mean, negative mean values for each time-dependent signal obtained for displacement, velocity and acceleration.

The investigation highlights that for a maximum wind speed of $16,98 \mathrm{~m} / \mathrm{s}$ the full-scale structure of the television tower behaves well at the conditions specific for Bucharest site, in Romania.

Since the results were obtained for a relatively low level of turbulence future research will focus on achieving a more accurate description of the oscillatory behaviour of the tower under the correct turbulent wind action. This issue will be very useful for the design process activity to have a complete picture of the behaviour of such an important building.

The authors acknowledge the modernization of the boundary layer wind tunnel TASL1-M from the Aerodynamics and Wind Engineering Laboratory "Constantin Iamandi", of the TUCEB performed under the Sectorial Operational Program "Increase of Economic Competitiveness", ctr. No. 646/20.03.2014 - ID 1900/ SMIS 49166.

\section{References}

1. ***, EN 1991-1-4, Eurocode 1: Actions on structures - Part 1-4: General actions - Wind actions (1991) https://www.phd.eng.br/wpcontent/uploads/2015/12/en.1991.1.4.2005.pdf

2. ***, CR 1-1-4/2012, Design code. Evaluation of wind action on constructions (trans. Cod de proiectare. Evaluarea actiunii vantului asupra constructiilor) (2012) http://ugir.ro/wpcontent/uploads/2012/06/CR-1-1-4-2012.pdf

3. E. K. Bandi, Y. Tamura, A. Yoshida, Y. C. Kim, and Q. Yang, Experimental investigation on 
aerodynamic characteristic of various triangularsection high-rise buildings, J. W. Eng. Ind. Aer., 122 , 60-68

(2013) https://doi.org/10.1016/j.jweia.2013.07.002

4. E. A. Chiulan, I. Popa, and A. Anton, Experimental study on an aeroelastic model of a television tower in the boundary layer wind tunnel, Bul. Trans. Univ.

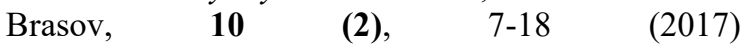
http://rs.unitbv.ro/Bulletin/Series\%20I/2017/BULET IN\%20I/Chiulan_E.A.pdf

5. E. A. Chiulan, I. Popa, A. C. Vlăduț, C. I. Coșoiu, A. M. Georgescu, A. Anton and M. Degeratu, Experimental investigation on the behavior of a tall and slender building placed in a turbulent boundary layer, IEEE Conf. Publications, 2017 Int. Conf. on Energy and Environment CIEM (2017) https://ieeexplore.ieee.org/document/8120792

6. R. O. Denoon, and K. C. S. Kwok, Fullscale measurements of wind-induced response of a $84 \mathrm{~m}$ high concrete control tower, J. W. Eng. Ind. Aer., 60, 155-165 (1996) https://doi.org/10.1016/0167$\underline{6105(96) 00030-X}$

7. J. Y. Fu, J. R. Wu, A. Xu, Q. S. Li, and Y. Q. Xiao, Full-scale measurements of wind effects on Guangzhou West Tower, Eng. Struct., 35, 725-739 (1998) https://doi.org/10.1016/j.engstruct.2011.10.022

8. A. M. Georgescu, C. Iamandi, and M. Degeratu, $A$ wind tunnel study for a TV tower in BucharestRomania, Proc. Urb. Eng. Asian Cities in the $21^{\text {st }}$ Cent., Bangkok, 1, 315-320 (1996) https://www.researchgate.net/publication/28326785 5 A WIND TUNNEL STUDY FOR A TV TO WER IN BUCHAREST- ROMANIA

9. P. A. Irwin, Wind-engineering challenges of the new generation of super-tall buildings, J. W. Eng. Ind. Aer., 97, 328-334 (2009) https://doi.org/10.1016/j.jweia.2009.05.001

10. F. A. Johann, E. N. M. Mazzilli, and F. L. S. Ricardo, Wind-induced motion on tall buildings, J. W. Eng. Ind. Aer., 142, 26-42 (2015) https://doi.org/10.1016/j.jweia.2015.03.001

11. Q. S. Li, Y. Q. Xiao, J. Y. Fu, and Z. N. Li, Fullscale measurements of wind effects on the Jin Mao Building, J. W. Eng. Ind. Aer., 95, 445-466 (2007) https://doi.org/10.1016/j.jweia.2006.09.002

12. A. Kareem, S. Kabat and F. L. Haan Jr., Aerodynamics of Nanjing Tower: A case study, J. W. Eng. Ind. Aer., 77-78, 60-68 (2013) https://doi.org/10.1016/S0167-6105(98)00187-1

13. A. M. Marra, C. Mannini, and G. Bartoli, Measurements and improved model of vortexinduced vibration for an elongated rectangular cylinder, J. W. Eng. Ind. Aer., 147, 358-367 (2015) https://doi.org/10.1016/j.jweia.2015.08.007
14. L. Rosa, G. Tomasini, A. Zasso, and A.M. Aly, Wind-induced dynamics and loads in prismatic slender building: A modal approach based on unsteady pressure measurements, J. W. Eng. Ind. Aer., 107-108, 118-130 (2012) https://doi.org/10.1016/j.jweia.2012.03.034

15. H. Tanaka, Y. Tamura, K. Ohtake, M. Nakai, and Y. C. Kim, Experimental investigation of aerodynamic forces and wind pressures acting on tall building with various unconventional configurations, J. W. Eng. Ind. Aer., 107-108, 179-191 (2012) https://doi.org/10.1016/j.jweia.2012.04.014

16. J. Xie, Aerodynamic optimization of super-tall buildings and its effectiveness assessment, J. W. Eng. Ind. Aer., 130, 88-98 (2014) https://doi.org/10.1016/j.jweia.2014.04.004

17. M. Degeratu, Dimensional Analysis, Similitude and Modeling- Guidance for Applications in Fluid Mechanics (trans. Analiza dimensională, similitudine și modelare- Indrumător pentru aplicații în mecanica fluidelor), Bucharest, Romania (2012) 